\title{
Paradoxical and less paradoxical effects of thought suppression: A critical review
}

Citation for published version (APA):

Rassin, E. G. C., Merckelbach, H. L. G. J., \& Muris, P. E. H. M. (2000). Paradoxical and less paradoxical effects of thought suppression: A critical review. Clinical Psychology Review, 20(8), 20-20. https://doi.org/10.1016/S0272-7358(99)00019-7

Document status and date:

Published: 01/01/2000

DOI:

10.1016/S0272-7358(99)00019-7

Document Version:

Publisher's PDF, also known as Version of record

\section{Please check the document version of this publication:}

- A submitted manuscript is the version of the article upon submission and before peer-review. There can be important differences between the submitted version and the official published version of record.

People interested in the research are advised to contact the author for the final version of the publication, or visit the DOI to the publisher's website.

- The final author version and the galley proof are versions of the publication after peer review.

- The final published version features the final layout of the paper including the volume, issue and page numbers.

Link to publication

\footnotetext{
General rights rights.

- You may freely distribute the URL identifying the publication in the public portal. please follow below link for the End User Agreement:

www.umlib.nl/taverne-license

Take down policy

If you believe that this document breaches copyright please contact us at:

repository@maastrichtuniversity.nl

providing details and we will investigate your claim.
}

Copyright and moral rights for the publications made accessible in the public portal are retained by the authors and/or other copyright owners and it is a condition of accessing publications that users recognise and abide by the legal requirements associated with these

- Users may download and print one copy of any publication from the public portal for the purpose of private study or research.

- You may not further distribute the material or use it for any profit-making activity or commercial gain

If the publication is distributed under the terms of Article $25 \mathrm{fa}$ of the Dutch Copyright Act, indicated by the "Taverne" license above, 


\title{
PARADOXICAL AND LESS PARADOXICAL EFFECTS OF THOUGHT SUPPRESSION: A CRITICAL REVIEW
}

\author{
Eric Rassin, Harald Merckelbach, and Peter Muris \\ Maastricht University
}

\begin{abstract}
The process of consciously trying to avoid certain thoughts is referred to as thought suppression. Experimental research has documented that thought suppression may have paradoxical effects in that it leads to an increased frequency of the to-be-suppressed thought intruding consciousness. It has also been claimed that suppression has disruptive effects on episodic memory (i.e., a less paradoxical effect). The present article critically evaluates studies on the paradoxical and less paradoxical effects of thought suppression. More specifically, the issue of whether thought suppression plays a causative role in the development of various psychopathological symptoms is addressed. While laboratory studies have come up with highly consistent findings about the paradoxical effects of thought suppression, there is, as yet, little reason to believe that such effects are implicated in the etiology of obsessions, phobias, or other psychopathological conditions. Relatively little work has been done on the alleged memory effects of thought suppression. The studies that have examined this issue have found mixed results. Accordingly, the case for the amnestic power of thought suppression is weak. Alternative explanations and competing theories are discussed, and it is concluded that research concerned with the psychopathological consequences of thought suppression would benefit from development of better taxonomies of intrusive thinking and cognitive avoidance strategies. (C) 2000 Elsevier Science Ltd.
\end{abstract}

KEY WORDS. Intrusions, Psychopathology, Thought suppression.

IN CLINICAL LITERATURE, the term "repression" may have various meanings. Yet, in most cases, it refers to defensive maneuvers that expel unwanted thoughts from conscious awareness. In a number of case studies, Sigmund Freud sought to document the pathogenic effect of repression. The hysteria of Dora, the phobia of Little

Correspondence should be addressed to Eric Rassin, Department of Psychology, Maastricht University, PO Box 616, 6200 MD Maastricht, The Netherlands. E-mail: E.Rassin@ Psychology.Unimaas.NL 
Hans, the obsession of the Ratman: All of these anecdotal testimonies were presented by Freud as support for the notion that repression is the vehicle behind highly diverse manifestations of psychopathology. Consider the example of the Ratman (S. Freud, 1955). This patient was plagued by the following obsession: He imagined punishing his father by fastening a pan with rats to his father's rectum. How is it possible that someone suffers from such a bizarre intrusion? Freud came up with this explanation: During his youth, the Ratman systematically repressed aggressive thoughts about his father, but as he grew older the repressed material surfaced in the form of a pathological obsession. According to Freud, the Ratman is a prototypical example of the antecedent role of repression in the development of psychopathology. Anna Freud further elaborated this idea and claimed that "Repression is the most dangerous defence mechanism (. . .) Repression is the basis for the formation of neurosis" (A. Freud, 1946 , p. 44). She argued that repression is an unconscious, automatic process. By this view, the person does not know that he/she tries to avoid certain thoughts (see, for an extensive analysis, Erdelyi, 1993).

To date, many research psychologists would argue that the Freudian view on repression is problematic. For example, Holmes (1990) summarized a large body of experimental studies concerned with repression and concluded that "despite over sixty years of research involving numerous approaches by many thoughtful and clever investigators, at the present time there is no controlled laboratory evidence supporting the concept of repression" (p. 96). A similar conclusion was reached by Eysenck (1985), who in his "Decline and Fall of the Freudian Empire" carefully reviewed research on repression and other Freudian concepts. Eysenck concluded that

what emerges again and again from examination of the empirical and experimental literature is that authors practically always fail to look at their studies and results from the point of view of psychological theory, to see whether they could have been predicted as well, or better, in terms well known to academic psychologists, rather than in Freudian terms. (pp. 159-160)

Unlike automatic and unconscious repression, deliberate attempts to remove thoughts from consciousness lend themselves much easier to experimental analysis. Wegner (1989) termed this type of mental avoidance "thought suppression," but the phenomenon was already extensively described by William James (1890). James assumed that an unwanted cognition can be avoided (suppressed) by shifting one's attention to another thought. He believed that in this way, people can regulate and control their stream of consciousness. Wegner is less optimistic about this possibility. He maintains that the mental control that people can exert over their stream of consciousness is limited. To illustrate this point, he asked undergraduates to suppress all thoughts about a cup of coffee for a 30-second period. Whenever the students thought about a cup of coffee, they had to ring a bell. The average frequency with which students thought about the to-be-suppressed item was 3.7. Interestingly, when undergraduates were instructed to concentrate on thinking about a cup of coffee for 30 seconds, their thoughts wandered away with an average frequency of 3.3 times. These findings led Wegner (1989) to conclude that people are not able to control their thoughts for periods longer than 10 seconds. He also noted that thought suppression has a paradoxical effect in that it enhances the frequency with which the suppressed thought surfaces in the stream of consciousness. This paradoxical effect would suggest that suppression may have a pathogenic potential. In the words of Wegner, Schneider, Carter, and White (1987): "The observed processes, though fairly 
tame in the laboratory, might conceivably create powerful mental preoccupations in natural settings" (p. 12).

This article reviews paradoxical and some less paradoxical effects of thought suppression and critically evaluates the claim that they play an antecedent role in certain manifestations of psychopathology. The article is structured as follows. First, experimental studies concerned with the paradoxical consequences of thought suppression are summarized. Next, the issue of thought suppression as a coping style or individual difference factor is addressed. In addition, evidence for the link between thought suppression and psychopathological phenomena is critically discussed. Then, potential treatment implications of research on thought suppression are addressed. The article closes with a brief discussion of fruitful research avenues for future studies.

\section{THE PARADOXICAL EFFECTS}

\section{The Basic Phenomena}

Systematic research on thought suppression only started after Wegner and colleagues (1987) published their by now classic "white bear" experiments. The general outline of their critical experiment was as follows. Normal subjects were assigned to one of two groups. The first group was an "initial suppression" group in which subjects were instructed to suppress the thought of a white bear for a 5-minute period. Following this, subjects were given expression instructions: That is, they were asked to think about a white bear during a 5 -minute period. In the second group, termed the "initial expression" group, the order of instructions was reversed. Here, subjects first engaged in expression and then in suppression. Subjects had to ring a bell whenever they thought of the target. Wegner and colleagues found that thought suppression produced an immediate enhancement effect. By and large, subjects who had received suppression instructions were unable to completely suppress the target thought: The mean frequency of white bear-thoughts during the suppression period was 6.8. Furthermore, during expression, subjects were found to think more intensively about a white bear (i.e., they rang the bell more frequently) when they had previously engaged in thought suppression. Apparently, then, suppression of an unwanted thought not only produces immediate enhancement, but also results in a higher frequency of this thought later on. Wegner (1989) referred to the latter phenomenon as "the rebound effect of thought suppression."

Thus, the pioneering work of Wegner (1989) showed that the paradoxical effects of thought suppression can manifest itself in two forms: an immediate and/or a delayed increase in the target thought. A number of subsequent studies have replicated both phenomena. For example, using "vehicle" in stead of "white bear" as a target thought, Lavy and Van den Hout (1990) reported an immediate enhancement effect similar to that described by Wegner et al. (1987). As another example, Clark and colleagues (Clark, Ball, \& Pape, 1991; Clark, Winton, \& Thynn, 1993) found that suppression of "green rabbit" thoughts produced a heightened level of intrusions about the pertinent item during a subsequent suppression-free period (i.e., a rebound effect).

Muris and Merckelbach (1991) collected data suggesting that the rebound effect of thought suppression is maintained over longer time intervals. In their study, undergraduates were asked to read a transcription of Freud's Ratman case (cf. supra). Half of the participants were then instructed to avoid all thoughts about this transcription for a 10-minute period, while the other half were free to think about anything. After 1 
week, all participants were interviewed about how often they had had thoughts related to the transcription over the past week. Participants who had engaged in suppression reported more thoughts (4.6) about the Ratman transcription than did control subjects (2.0). Paradoxical effects of thought suppression are not restricted to situations in which people suppress personally irrelevant targets (e.g., white bears or other people's obsession). For example, Roemer and Borkovec (1994) noted that suppression of personally relevant anxious or depressing themes leads to a subsequent enhancement of these themes. Although not all researchers were able to replicate the immediate and/or delayed paradoxical effects following suppression (e.g., Kelly \& Kahn, 1994; Muris, Merckelbach, Van den Hout, \& De Jong, 1992; Smári, Sigurjónsdóttir, \& Sæmundsdóttir, 1994; Wegner, Quillian, \& Houston, 1996), the bulk of the literature suggests that these effects are quite robust.

One may argue that paradoxical effects of thought suppression are artifacts elicited by, for example, instructions to ring a bell whenever the unwanted thought occurs. However, paradoxical effects of thought suppression can also be documented when subjects give aposterio estimates of the frequency of the to-be-suppressed material (e.g., Clark et al., 1991). In general, individuals seem to be very sensitive to frequency information. For example, Brown (1990) had her subjects rate frequency of appearance of actors in a TV soap and found that the correlation between subjective frequency estimates and actual time on screen approached 0.91. Note further that paradoxical effects of thought suppression are not limited to self-reported frequencies, but may also become apparent at a behavioral level. Germane to this issue is a study by Cioffi and Holloway (1993) who noted that suppression of pain sensations has paradoxical effects on recovery from pain. These authors examined thought suppression effects in subjects who underwent a cold pressor task. In this study, subjects were assigned to one of three conditions: suppression, distraction, and monitoring (i.e., paying close attention to physical sensations) and then had to carry out a cold pressor task. That is, they were instructed to keep their hand in ice-water for as long as they could tolerate. After this task, subjects had to rate levels of post-pressor pain on Visual Analogue Scales (VAS's). Results showed that suppression subjects had significantly higher VASratings, indicating that they recovered more slowly from pain than distraction and monitoring subjects. Furthermore, in anticipation of a second cold pressor task, subjects who had previously engaged in suppression, displayed a greater heart rate acceleration and lower self-efficacy to withstand the task than did subjects in the other conditions.

As another example, Wegner, Shortt, Blake, and Page (1990) demonstrated that suppression of an exciting thought, promotes physiological reactivity as indexed by heightened skin conductance levels. Interestingly, behavioral consequences of thought suppression have also been documented in social psychology literature. Macrae, Bodenhausen, Milne, and Jetten (1994) conducted an experiment in which they showed their participants a photograph of a male skinhead. Subjects were invited to describe what a typical day of the person in the photo may look like. Half of the participants were instructed to avoid stereotypic ideas about skinheads while engaging in that task. The other half was given no such instructions. Following this, participants were told that they would meet the skinhead. In anticipation of this meeting, they were asked to take a seat. Subjects were free to choose between seven seats. The eighth seat was evidently occupied by the skinhead, as a jacket and a bag were on it. Participants who had been instructed to avoid stereotypic ideas and control subjects were compared to each other with respect to two dependent measures, namely, the fre- 
quency of stereotypes in the descriptions of a typical day of the skinhead and preferred seating position. While suppression subjects gave less stereotypes in their descriptions than did controls, they preferred to sit further away from the skinhead's belongings than control subjects. Thus, these results suggest that suppression of stereotypic thoughts does result in a paradoxical rebound effect at a behavioral level. Taken together, these findings indicate that artifactual explanations of the paradoxical effects of suppression are themselves open to question.

\section{Why Do Paradoxical Effects Occur?}

Wegner (1989) speculated that when people try to avoid a certain thought, they often do so by shifting their attention to an irrelevant environmental item. However, the target thought will come to mind during such distraction attempts and consequently, the initially irrelevant item (the distracter) becomes associated with the target thought. In this way, the irrelevant item is converted into a retrieval cue for the to-be-suppressed information. Hence, the person will look for a new distracter. Iteration of this associative process results in a higher frequency of intrusions, simply because the person will find himself surrounded by various stimuli that remind him of the to-be-suppressed thought. Evidence for this so-called "environmental cueing" process comes from an experiment in which the external distracters were manipulated (Wegner, Schneider, Knutson, \& McMahon, 1991; see also Muris, Merckelbach, \& De Jong, 1993). While engaging in suppression of white bear thoughts, subjects watched a series of slides. Following suppression, they were instructed to think about a white bear. When this was done in the context of the series of slides that were initially shown, a rebound effect occurred. Yet, when the context was changed, by showing a new series of slides, no rebound was observed.

Recently, Wegner (1994) formulated a more elaborated version of the environmental cueing hypothesis. According to this more recent version, thought suppression activates two opposing processes. The first one is a conscious and effort-demanding "operating process" that searches continually for distracting stimuli. The second one is an unconscious and relatively effortless "monitoring process" that is sensitive to occurrences of the unwanted thought. This monitoring process is triggered by attempts to control the stream of consciousness and is maintained until such attempts are given up. As the operating process is a conscious and capacity-limited process, it suffers from concurrent operations that require cognitive effort. In contrast, the monitoring process is relatively unaffected by other mental operations. This difference may lead to an imbalance, in which the monitoring process overrules the operating process, which in turn results in an increased detection of unwanted thoughts. Indirect support for Wegner's theory comes from studies (e.g., Wegner \& Erber, 1992) demonstrating that thought suppression is less effective when subjects are involved in a concurrent task that also requires the operating process. For example, subjects who carry out a word association task with time pressure, are less capable of suppressing a thought than subjects who carry out a word association task without time pressure. Emotions are also said to interfere with optimal functioning of the operating process. By this view, anxious or depressed subjects would be less successful in suppressing unwanted thoughts (Wenzlaff, Wegner, \& Roper, 1988). Interestingly, Bowers and Woody (1996) found evidence to suggest that the paradoxical effects of thought suppression fail to occur in hypnotized individuals, an observation that makes sense if 
one assumes that hypnosis promotes a state in which the intentional operating process is bypassed.

\section{Directed Forgetting}

Remarkably, a completely different line of research referred to as "directed forgetting" indicates that when subjects receive a "forget" instruction, they can successfully forget target stimuli (see, for an overview, Johnson, 1994). In directed forgetting experiments, subjects are presented with two separate lists of words. One of these lists is to be forgotten, while the other is to be memorized. After a short delay, subjects are asked to recall all words, including those presented in the forget-list. In general, subjects reproduce more items from the remember-list than from the forget-list. The directed forgetting paradigm can be extended by varying the emotional valence of the words. For example, both lists may contain positive (e.g., "merry") and negative words (e.g., "anxious"). Strikingly, the directed forgetting effect tends to be greater for negative than for positive words, especially in so-called repressors, that is, individuals who are highly defensive and at the same time low-anxious (Myers, Brewin, \& Power, 1998). These results seem to indicate that people can forget target stimuli, especially negative target stimuli when they are instructed to do so. It is worth noting that studies concerned with the rebound effect of thought suppression have often failed to find such an interaction between avoidant strategies and target valence (e.g., Harvey \& Bryant, 1998a; Roemer \& Borkovec, 1994). In fact, the finding that thought suppression elicits paradoxical phenomena in negative, neutral, and positive target material led Harvey and Bryant (1998a) to conclude that thought suppression may not be a valid paradigm for clinical intrusions. Thus, in several respects, directed forgetting research seems to contradict literature on thought suppression. It is important to stress, though, that there are important technical differences between directed forgetting and thought suppression paradigms. Most importantly, in directed forgetting experiments, the forget-list is presented as a practice task that precedes the real memory task. For example, Myers and colleagues (1998) instructed their subjects as follows: "What you have done so far has been practice. You can forget about those words. I will now show you the actual set of test words ..." (p. 143). Yet, in a suppression experiment, the instruction might have been more like: "I want you not to think about the words I have just shown you." These instructions communicate quite different actions. In directed forgetting, subjects are allowed to ignore the targets, while they should concentrate on words presented on a subsequent remember-list. Thus, subjects are given a strong distracter for a target that has been trivialized. In contrast, in suppression studies, the target thought is made outstanding by the simple act of presenting it as the to-be-suppressed target, while no distracter is provided. The consequence of this is that subjects attend to a large array of environmental stimuli that become retrieval cues of the to-be-suppressed thought. Interestingly, Wegner and colleagues (1987; exp. 2) noted in a follow-up experiment that a rebound effect of suppression does not occur when subjects are given instructions to focus on one single, outstanding distracter (e.g., red Volkswagen) whenever the to-be-suppressed thought comes to mind. This suggests that distracters may, indeed, play a vital role in whether or not suppression produces a preoccupation with the target material.

The technical differences between directed forgetting and thought suppression paradigms may explain the conflicting results that these two research lines have generated. Meanwhile, the question arises which paradigm is more ecologically valid as a 
model for real life obsessive intrusions. It is intuitively plausible to argue that thought suppression has more everyday equivalents than does directed forgetting. Even so, the precise differences between both paradigms warrant further study. So far, research on thought suppression has largely ignored the phenomenon of directed forgetting.

\section{THOUGHT SUPPRESSION AND PSYCHOPATHOLOGY}

\section{Individual Differences in Thought Suppression Tendencies}

Results obtained by Merckelbach, Muris, Van den Hout, and De Jong (1991) indicate that people differ in how successful they are at thought suppressing. These authors found a positive relationship $(r=.59, n=35, p<.001)$ between the number of intrusions during suppression and the frequency of intrusions during control periods (see also Rutledge, Hollenberg, \& Hancock, 1993). That is, subjects who reported a high frequency of intrusions when they tried to suppress a certain thought, also displayed a stronger rebound effect during subsequent suppression-free periods. This suggests that an individual difference factor is at work in the paradoxical effects of thought suppression.

To measure individual differences in the motivation to suppress unwanted thoughts across a wide range of situations, Wegner and Zanakos (1994) developed a 15-item questionnaire that they termed the White Bear Suppression Inventory (WBSI). Typical examples of WBSI-items are: "I wish I could stop thinking of certain things" and "I have thoughts that I cannot stop." WBSI-items are scored on 5-point scales (anchors: $1=$ strongly disagree, $5=$ strongly agree). A total score is calculated by summing across the items. Accordingly, a high WBSI-score would indicate a strong tendency to suppress unwanted thoughts. Wegner and Zanakos, as well as Muris, Merckelbach, and Horselenberg (1996), found that the psychometric qualities of the WBSI are satisfactory. To illustrate, in the Muris et al. study, internal consistency of the WBSI was good (Cronbach's $\alpha=.89 ; n=172$ ) and test-retest stability (12-week interval) proved to be adequate $(r=.80 ; n=40 ; p<.001)$. That study also found that subjects with high WBSI-scores subsequently report more intrusions in an experimental thought suppression set-up than subjects with low WBSI-scores, suggesting that the WBSI possesses predictive validity. Taken together, it is safe to assume that the WBSI is sensitive to individual differences in the extent to which people rely on thought suppression as a general mental control strategy. As people who try to suppress unwanted thoughts are, in fact, very poor at it, Wegner and Zanakos (1994) reasoned that a chronic and generalized tendency to suppress thoughts may serve as a risk factor for psychopathological conditions. In their words, "chronic thought suppression should cause symptoms of obsession, depression, and anxiety" (p. 619). We now turn to studies that sought to explore the psychopathological ramifications of thought suppression.

\section{Obsessive Compulsive Disorder}

There are reasons to believe that the paradoxical effects of thought suppression are not restricted to the laboratory. According to Wegner (1989), suppression may contribute to the obsessive nature of an initially relatively harmless (nontraumatic) thought: "An obsession can grow from nothing but the desire to suppress a thought" (p. 167). Thus, Wegner claims that the vicious circle of suppression, rebound, and 
again (more) suppression, and (more) rebound may be sufficient to transform a neutral thought into an obsessive intrusion.

Indirect support for the idea that thought suppression plays a role in the development of pathological obsessions comes from various sources. To begin with, Muris et al. (1996) found in a nonclinical sample a significant correlation $(r=.35, p<.001)$ between WBSI-scores and scores on the Maudsley Obsessive-Compulsive Inventory (MOCI). A similar correlation was reported by Wegner and Zanakos (1994). Following a different research strategy, Trinder and Salkovskis (1994) found evidence to suggest that suppression contributes to the development of obsessions. These authors asked healthy volunteers to identify a recent negative intrusive thought. Next, subjects were assigned to one of three conditions: a suppression group, an expression group (in which subjects were instructed to think explicitly about the identified thought whenever it occurred), and a no-instruction group. Subjects were told to record for a 4-day period the number of times the pertinent thought intruded their consciousness as well as the degree of discomfort whenever this happened. Thereto, they were given a postcard on which they were instructed to put a tick every time the thought came to mind. Suppression subjects reported more intrusions and greater discomfort than control subjects. This suggests that suppression not only leads to a heightened frequency of intrusions, but may also change the emotional evaluation of the intrusion.

Smári, Birgisdóttir, and Brynjólfsdóttir (1995) found, in a nonclinical sample, that high scores on the MOCI predict a relatively strong paradoxical effect of suppression instructions. In subjects scoring low on the MOCI, such an effect was absent. Further evidence for the link between suppression and obsession is of a more inferential nature and can be found in, for example, the often cited Rachman and De Silva (1978) study on normal and abnormal obsessions. One of the main conclusions of that study was that obsessive intrusions in Obsessive Compulsive Disorder (OCD) patients and normals have a highly similar content, yet, do differ in terms of frequency, intensity, discomfort, and, most pertinent to the present discussion, resistance (or if one likes: suppression). The fact that the content of intrusive thinking does not differentiate between normal and clinical obsessions points in the direction of a continuum between both categories of obsessions. Aspects like the urge to resist obsessions rather than their content would characterize the clinical range of this continuum (see also Rachman, 1997). The pioneering work of Rachman and De Silva was replicated by Salkovskis and Harrison (1984). These authors also noted a close link between resistance and frequency of obsessive intrusions.

Recent studies suggest that thought suppression may also be involved in compulsive behaviors. For example, Muris, Merckelbach, and Clavan (1997) compared rituals of normal subjects with those of OCD patients. As is true for obsessive intrusions, normal and abnormal compulsions were found to be highly similar in content. Yet, the two categories of rituals did differ in terms of frequency, intensity, discomfort, and, again, resistance. A study by Rassin, Merckelbach, Muris, and Stapert (1999) further investigated the relationship between thought suppression and ritualistic behaviors in normal subjects. More specifically, these authors examined rituals of subjects with high and low WBSI-scores. As expected, high WBSI-subjects experienced their rituals as more intense, more discomforting, and more resistance-provoking than low WBSIsubjects. These findings are consistent with the notion that thought suppression plays a role in the development of pathological compulsion.

The question arises whether thought suppression and its paradoxical effects really act as antecedents in the etiology of pathological intrusions and rituals. Although the 
research discussed above strongly suggests such a causal link, there are more articulated accounts of the development of OCD symptoms. For example, some authors (Rachman, 1993, 1997, 1998; Shafran, Thordarson, \& Rachman, 1996) have pointed out that a certain type of cognitive bias known as thought-action fusion (TAF) rather than suppression per se underlies the etiology of pathological obsessions. Briefly, TAF refers to an overvaluation of intrusive thoughts, such that unwanted thoughts are appraised as equivalents of unwanted action. An example would be the belief that unacceptable thoughts are as bad as the actual actions they describe. It is easy to see how TAF could contribute to an inflated sense of responsibility and, subsequently, to suppression and neutralization attempts. Thus, according to this analysis, the primary antecedent of obsessive intrusions would be TAF, while suppression can be conceptualized as a secondary and possibly counterproductive reaction to TAF-intrusions. A recent laboratory study by Rassin, Merckelbach, Muris, and Spaan (1999) explored the effects of experimentally induced TAF. In this experiment, adolescent subjects underwent a bogus EEG-recording session. Subjects in the experimental group were informed that the apparatus was able to pick up the word "apple" and that thinking of that word could result in the administration of electrical shocks to a person in an adjacent room. Subjects in the control group were told that the EEG-equipment was sensitive to "read" simple words such as "apple" and were asked to sit quietly and relax. After having spent 15 minutes in the EEG-laboratory, experimental and control subjects completed a short questionnaire containing items about characteristics (e.g., frequency, aversiveness) of the target thought. Results showed that subjects in the experimental group reported a higher frequency of target thoughts, more discomfort, and a greater urge to suppress compared to subjects in the control group. These findings are consistent with the idea that TAF promotes intrusive thinking and that it precedes suppression attempts. Such an interpretation is further supported by a recent study of Rassin, Muris, Schmidt, \& Merckelbach (in press). In that study, 173 students completed the TAF-scale (Shafran et al., 1996), WBSI, and MOCI. Structural equation modeling was used to explore the best fitting causal relationships between the scores on these scales. Results suggested that a TAF bias triggers suppression tendencies, while these tendencies increase obsessive-compulsive symptoms. Thus, again, the interpretation of intrusions (i.e., the TAF bias) seems to be a more fundamental cause of obsessive-compulsive symptoms than the tendency to suppress intrusions. Given these preliminary results, there is a clear need for future studies in which TAF and suppression are manipulated simultaneously. Such parametric studies could shed further light on the precise dynamics between these factors.

\section{Generalized Anxiety Disorder, Phobia, and Depression}

Becker, Rinck, Roth, and Margraf (1998) examined effects of suppression in patients with Generalized Anxiety Disorder (GAD) and normal controls. While GAD patients and controls did not differ in their ability to suppress neutral material (e.g., white bears), GAD patients found it harder to suppress thoughts about their recent worries. More specifically, GAD patients displayed an immediate enhancement effect when they tried to suppress their main worry, whereas controls did not show such an effect. The authors take this as evidence to conclude that "patients with GAD do indeed suffer from a lack of mental control regarding their worries" (Becker et al., 1998, p. 51). But, of course, these findings do not show that thought suppression is the vehicle behind worries in GAD. Indeed, in literature a radically different perspective on GAD 
(e.g., Dugas, Gagnon, Ladouceur, \& Freeston, 1998) can be found, a perspective which conceptualizes worrying as a cognitive reaction to intolerance of uncertainty. By this view, worrying is an act of avoidance of fear provoking imagery that develops as a consequence of ambiguous "what if" problems. Evidence to support this line of reasoning comes from the work of Borkovec and co-workers (e.g., Borkovec \& Inz, 1990) who demonstrated that worrying has an inhibitory effect on physiological reactivity to phobic imagery. This suggests that rather than being preceded by mental avoidance maneuvers such as suppression worrying is an act of mental avoidance.

Muris, De Jongh, Merckelbach, Postema, and Vet (1998) examined the role of thought suppression in dental phobia. Nonphobic and phobic patients were instructed to suppress or to express (i.e., think about) negative dentist-related thoughts while undergoing dental treatment. As expected, phobic patients exhibited higher levels of suppression and intrusive thinking than nonphobic patients. However, only in the nonphobic group, suppression instructions produced a significant enhancement in intrusive thinking and anxiety. The counterproductive effects of thought suppression did not occur in the phobic group. Comparable results were reported for another type of specific phobia, namely spider phobia (see Muris, Merckelbach, Horselenberg, Sijsenaar, \& Leeuw, 1997). Thus, as things stand, there is no ground for suspecting that thought suppression plays an important role in the etiology of phobias.

As to the link between suppression and depression, Kuyken and Brewin (1994) found in their cross-sectional study of depressed women that those women with particular high levels of intrusion and avoidance were also more severely depressed. Yet, as these authors themselves admit, the direction of causality awaits further study. Wenzlaff et al. (1988) noted that depressed individuals exhibit a deficit in the ability to suppress unwanted, negative thoughts. More specifically, their results show that the efficacy of depressed subjects' suppression efforts is short-lived in that suppression attempts are accompanied by a resurgence of unwanted thoughts about the negative item (see, for similar findings, Conway, Howell, \& Giannopoulos, 1991). Perhaps, then, depression undermines mental control over negative thoughts, thereby strengthening the paradoxical effects of thought suppression. But, note that in this analysis, suppression is a by-product rather than a determinant of depressive mood. This interpretation nicely fits with Rachman's (1981) view that dysphoria contributes to the persistence of intrusions by impairing mental control over these intrusions. Note that there is suggestive evidence for Rachman's position (e.g., Clark, 1992).

\section{Addiction}

A number of studies have explored whether suppression promotes smoke-related intrusions in ex-smokers. In an experiment by Salkovskis and Reynolds (1994), 62 ex-smokers were assigned to one of three groups: a suppression group (in which subjects were instructed to suppress thoughts about smoking), an expression group (in which subjects just had to record thoughts about smoking), or a relaxation group (in which subjects carried out breathing exercises that distracted them from smoking-related thoughts). Results demonstrated that all subjects frequently experienced intrusive thoughts about smoking and that they had difficulty in controlling such thoughts. Yet, subjects in the suppression group exhibited an increased frequency of intrusions compared to the other two groups. In a related study, Haaga and Allison (1994) retrospectively examined the connection between coping style and smoking relapse. The authors found that the strategies employed by ex-smokers to maintain abstinence in case of strong urges to 
smoke can be reduced to two broad coping styles: cognitive restructuring (e.g., thinking about negative health consequences) and thought suppression. Subjects were interviewed on two occasions: 3 to 12 months after they had given up smoking. On both occasions, subjects who successfully stopped smoking more often employed the strategy of cognitive restructuring, compared to subjects who relapsed. This suggests that cognitive restructuring is a good predictor of successful smoking cessation, but it does not necessarily imply that thought suppression is involved in relapse.

Stronger evidence for the detrimental effects of thought suppression comes from Palfai, Monti, Colby, and Rohsenow (1997), who examined the role of suppression in heavy social drinkers. A group of heavy social drinkers was exposed to the sight and smell of their usual alcohol beverage. During this exposure, half of the subjects were instructed to suppress their urge to drink alcohol, while the other half did not receive these instructions. Following this, subjects carried out a cue reactivity task in which they were asked to make judgments about a series of alcohol outcome expectancies. Results showed that subjects in the suppression condition were faster to endorse alcohol outcome expectancies following exposure to alcohol cues than subjects in the control condition. Thus, suppression seemed to increase the accessibility of alcohol related information.

\section{Trauma-related Psychopathology}

While avoidance and intrusions are hallmark features of Acute Stress Disorder (ASD), there has been only one study investigating the effects of thought suppression in this condition. In that study, Harvey and Bryant (1998b) examined survivors of motor vehicle accidents with and without ASD. Subjects monitored their trauma-related thoughts for three 5-minute periods. During period 1 (i.e., baseline), subjects were allowed to think about anything. During period 2, subjects were given either suppression or nonsuppression instructions in relation to thoughts of the trauma. In period 3, subjects were, again, instructed to think about anything. Results showed that ASD subjects reported higher levels of anxiety, trauma-related thoughts, and suppression than non-ASD subjects. Most interestingly, ASD subjects who were given suppression instructions, demonstrated a rebound effect, that is, an increased frequency of traumarelated intrusions in the period subsequent to suppression.

Like ASD, Post Traumatic Stress Disorder (PTSD) is characterized by intrusive thoughts about the traumatic incident and efforts to avoid such thoughts (American Psychiatric Association [APA], 1994). Amir et al. (1997) found that PTSD patients $(N=46)$ reported thought suppression to be the most frequent cognitive reaction to traumatic intrusions. In this regard, the PTSD patients differed from non-PTSD anxiety disorder patients and healthy controls. Apparently, then, ASD and PTSD patients try to rely on thought suppression to avoid recollections of their traumatic experience. As with obsession, one may speculate that such avoidance maneuvers will generate more thoughts about the trauma (i.e., the paradoxical effect; see McFarlane, 1988). Evidence that adds weight to this view comes from a study by Lawrence, Fauerbach, and Munster (1996), who interviewed 23 burn patients on the day of their discharge from the hospital and at a 4 months follow-up. On both occasions, patients completed the Impact of Event Scale, a self-report scale measuring cognitive avoidance (i.e., suppression) and intrusive thinking. Avoidance at the time of discharge significantly predicted the occurrence of intrusions 4 months later $(r=.59, p<.01)$. Similarly, Bryant and Harvey (1995) found in their sample of 56 motor vehicle acci- 
dent victims that avoidance was significantly associated with intrusive thinking 1 year after the accident $(r=.56, p<.01)$. As another example, Shipherd and Beck (1999) invited 36 women who were victims of sexual assault to participate in a suppression experiment. Seventeen of these women suffered from PTSD, while the remaining 19 did not completely fulfill DSM-IV criteria for PTSD, although they did suffer from subclinical PTSD symptoms. All women underwent three 9-minute periods, the first of which was spent thinking of anything. During the second period, women were instructed to suppress thoughts about the sexual assault. During the last period, women were told that they could think of anything including the assault. Results indicated that subjects in both groups were equally successful in suppressing trauma related thoughts. However, PTSD patients suffered from a rebound of intrusive thoughts during the third period, while controls did not display such a rebound effect.

While the studies summarized thus far seem to imply that in PTSD, suppression precedes intrusion, there are also longitudinal studies that found evidence for the opposite pattern. For example, Creamer, Burgess, and Pattison (1992) found that in 158 witnesses to a multiple shooting, avoidance predicted stress at 4 months, but not at 14 months after the trauma. On the basis of this observation, these authors noted that "intrusion precedes escape and avoidance, with the latter conceptualized as coping strategies, albeit often maladaptive, in response to discomfort that results from intrusive memories" (Creamer et al., 1992, p. 454). In a similar vein, Cella, Perry, Kulchycky, and Goodwin (1988) interviewed close relatives of hospital burn patients on three occasions: during the acute phase of hospitalization, at a 7-week follow-up, and a 7-month follow-up. The data collected through these interviews led the authors to conclude that intrusive symptoms receded more rapidly than avoidant coping strategies. Note that these findings are consistent with the work of Foa, Riggs, and Gershuny (1995) on the structure of PTSD symptoms. Their work suggests that intrusions give rise to active avoidance rather than the other way around. These authors also concluded that many victims who do not meet the full criteria for PTSD report thought suppression and intrusions. It is the passive avoidance implicated in symptoms of numbing that differentiates victims with and without PTSD. Clearly, these findings cast doubt on the idea that thought suppression acts as an important antecedent in the radicalization of PTSD symptoms.

\section{Conclusion}

The studies reviewed in this section demonstrate that thought suppression maneuvers do figure in a wide variety of mental problems and disorders. Even so, the case for a pathogenic role of thought suppression in these disorders is weak. While the paradoxical effects of thought suppression were originally invoked to account for obsessive intrusions, a more recent and more sophisticated explanation emphasizes the antecedent role of thought-action fusion, rather than thought suppression per se, in the development of obsessions. Likewise, in the case of worrying, there is an alternative conceptualization that stresses intolerance of uncertainty as a precursor of worrying. Clearly, thought suppression does occur as an accompanying feature in phobias and depressive mood, but there is no reason to suspect that it has a causative status in these disorders. This might also be true for ASD and PTSD in which the temporal dynamics suggest that intrusions may fuel thought suppression rather than vice versa. The most robust evidence for the involvement of thought suppression in the radicalization of symptoms comes from research on addiction and cue reactivity. Here, there 
are some indications that thought suppression may enhance cue reactivity and, consequently, may contribute to relapse. However, the preliminary character of the work in this domain precludes firm conclusions about the robustness of the link between thought suppression and relapse.

\section{THOUGHT SUPPRESSION AND MEMORY}

It is widely believed that adults who have experienced traumatic childhood events may cope with these experiences by engaging in selective suppression of traumatic memories (e.g., Brett \& Ostroff, 1985; Terr, 1991, 1993). By this view, selective "forgetting" or thought suppressing would underlie psychogenic, or in DSM-IV terms dissociative, amnesia, that is, "an inability to recall important personal information, usually of a traumatic or stressful nature, that is too extensive to be explained by ordinary forgetfulness" (APA, 1994, p. 477). There are at least two reasons why this view is problematic. To begin with, it remains to be seen whether neurologically intact individuals can develop amnesia for traumatic events. For example, on the basis of an extensive review of retrospective and prospective studies, Pope, Hudson, Bodkin, and Oliva (1998) concluded that the phenomenon of dissociative amnesia itself remains unproven. These authors point out that the main problem of studies with dissociative amnesia is that they equate nonreporting of trauma with dissociative amnesia, thereby ignoring the possibility that such nonreporting results from people's reluctance to disclose sensitive autobiographical material (see also Lilienfeld \& Loftus, 1998). Second, even if it is taken for granted that dissociative amnesia exists, it is doubtful whether thought suppression would be the critical mechanism involved. Of particular relevance to this issue is Wegner and Erber's (1992) observation that suppression of target thoughts leads to hyperaccessibility of these thoughts. In their experiments, Wegner and Erber demonstrated that especially under conditions of high mental load, suppression of certain targets makes these targets extremely well retrievable during, for example, word-association or Stroop color tasks. Findings such as these are difficult to reconcile with the idea that "the deliberate act of setting a memory aside leads easily to its permanent removal from consciousness" (Terr, 1991, p. 15). Much the same is true for the finding that women with parental abuse histories display an enhanced directed remembering rather than an enhanced directed forgetting of targets (e.g., negative words; Cloitre, Cancienne, Brodsky, Dulit, \& Perry, 1996; see also McNally, Metzger, Lasko, Clancy, \& Pitman, 1998).

While total dissociative amnesia is an unlikely scenario in traumatized people, incomplete recollections of traumas do occur. Germane to this issue is a study by Koss, Figueredo, Bell, Tharan, and Tromp (1996) who found that traumatic memories of rape victims are less clear and vivid, less detailed, and less likely to occur in the original order compared to memories of pleasant events. Although these characteristics can be attributed to an attentional narrowing effect during encoding (Wessel, 1997), Koss et al. argue that they might also originate from an avoidant coping style (e.g., thought suppression). In contrast to what one may expect on the basis of experimental thought suppression research, yet in line with the findings of Koss et al. (1996), recent studies have claimed that thought suppression may have memory undermining effects (Wegner et al., 1996). In the critical experiment, Wegner and colleagues (1996) exposed subjects to a film fragment and then assigned them to one of three 
conditions: a suppression condition (in which subjects had to suppress thoughts about the film), an expression condition (in which subjects were encouraged to think about the film), and a no-instruction control condition. Five hours later, subjects' memories about the film were tested. Results showed that whilst subjects in all three conditions scored equally on questions about the content of the fragment, suppression subjects performed significantly worse on questions addressing the chronology of events in the film fragment. Suppression also affected meta-memory representations of the film in that suppression subjects thought more of the film as a collection of isolated pictures (i.e., snapshots) compared to subjects in the expression and control conditions. While the observed effect was small and was restricted to memory for sequence of the film fragment, these results suggest that suppression may undermine episodic memory. Accordingly, Wegner et al. (1996) contend that the memory-out-oforder effects of thought suppression might in extreme cases lead to partial (psychogenic) amnesia. In their words: "The snapshot effect of suppression suggests that people might indeed do something that resembles the effect attributed to classical repression (...) it does yield a new way to think about how traumatic events might conceivably be lost to memory" (Wegner et al., 1996, p. 689). Apart from the experimental evidence provided by the Wegner et al. study, there is some indirect evidence for the memory undermining effects of thought suppression. In two subsequent studies (Muris \& Merckelbach, 1997; Van den Hout, Merckelbach, \& Pool, 1996), a positive and significant correlation between the WBSI and the Dissociative Experiences Scale (DES) was found ( $r=.52$ and $r=.35$, respectively). Frankel (1990) has argued that a number of DES items "can be readily explained by the manner in which subjects recall memories" (p. 827). Thus, it may well be the case that the DES taps memory problems that occur in those subjects who have a strong tendency to suppress.

The less paradoxical, that is, memory undermining effect of thought suppression seems to run counter to the hyperaccessibility that characterizes the paradoxical effects of thought suppression. Note, however, that there are important differences in the experimental set-up of studies concerned with memory effects of thought suppression and those concerned with hyperaccessibility effects. Whereas studies on the paradoxical effects of thought suppression focus on how thought suppression affects the frequency of relatively simple target thoughts, research on memory effects of thought suppression employs more complex stimuli such as film scenes. Nevertheless, Wegner and colleagues (1996) suggest several ways in which the paradoxical and memory disturbing effects of thought suppression might co-exist. For example, these authors speculate that suppression promotes the hyperaccessibility of highly specific film scenes. The hyperaccessible scenes then become outstanding memory details that overshadow sequence information. While such an interpretation reconciles the hyperaccessibility and memory disturbing effects of thought suppression, several critical points can be raised. First, in the Wegner et al. (1996) study, suppression subjects did not report an increased frequency of film related thoughts. Thus, hyperaccessibility does not seem to be a conditio sine qua non for "memories out of order." Second, Rassin, Merckelbach, and Muris (1997) failed to replicate the memory-out-of order effect of suppression, although they did find a hyperaccessibility effect. The film fragment used by Rassin and colleagues differed in two important ways from the type of film scenes in Wegner et al. studies. First, it was of shorter duration (3 minutes vs. 10 minutes in the Wegner et al. studies). Second, the fragment employed by Rassin et al. had an emotional content, whereas the Wegner et al. (1996) fragments were "interest- 
ing, but nontraumatic" (p. 682). The fact that thought suppression fails to produce a deficient memory of chronology when emotional material is involved, casts doubts on the speculation that thought suppression plays a role in partial amnesia.

In sum, then, while there is some circumstantial evidence to suggest that thought suppression has a negative effect on episodic memory, the precise details of this connection are not well-understood. Further studies are needed to define the robustness, limits, and variations of the memory-out-of-order effect of thought suppression.

\section{IMPLICATIONS FOR THERAPY}

Wegner (1989) is clear about the lessons for treatment to be learned from thought suppression studies: "in many cases of unwanted thought, it may be best to stop suppressing” (p. 174). According to Wegner, thought suppression experiments provide a straightforward rationale for habituation- or exposure-oriented treatments. In clinical literature, some good examples can be found that seem to underline Wegner's position. Thought stopping is a case in point. In thought stopping treatment, the patient is instructed to circumvent an obsessive intrusion by saying "stop" whenever it occurs. The efficacy of this intervention is, at best, modest (Marks, 1987), which is not surprising given the close parallels between thought suppression and thought stopping. Systematic exposure to obsessive intrusions appears to be a more promising treatment strategy. To illustrate, Salkovskis and Westbrook (1989) tape-recorded obsessive thoughts of their patients and then instructed these patients to listen to the tapes for several days at selected times. Patients were also taught how to refrain from covert avoidance tendencies (e.g., thought suppression). The combination of exposure and response prevention led to a decrease in obsessive thoughts and this positive outcome was maintained at long-term follow-up.

Taped habituation and prevention of thought suppression tendencies may also be fruitfully applied to other types of psychopathology. For example, Vaughan and Tarrier (1992) asked PTSD patients to describe their traumatic experiences and these descriptions were then audiotaped. Patients were instructed to listen to the audiotaped traumas for 1 hour per day over a 1-week period. They were also taught not to react with thought suppression to these tapes. Most of the patients benefited from treatment and this positive effect was maintained at 6 months follow-up. Likewise, Reynolds and Tarrier (1996) instructed PTSD patients to monitor their traumatic intrusions by keeping a detailed diary over a 2-month period. This resulted in an overall improvement such that at the end of the study, four out of six patients no longer met PTSD-criteria. Thus, confrontation with and elaboration of unwanted, negative thoughts seem to be effective elements in the treatment of PTSD. This is further illustrated by studies in which individuals had to write about personally upsetting events over and over again (e.g., Pennebaker, 1993; see also Esterling, L'Abate, Murray, \& Pennebaker, 1999). In general, positive outcomes in terms of physical and mental health have been reported in studies that relied on this diary method.

The studies cited above accord well with Wegner's (1989) suggestion that confronting an unwanted thought is a good starting point for treatment. However, this conclusion needs to be qualified. To begin with, it remains to be determined to what extent abstinence from thought suppression is a mediator of therapeutic success in the treatment of obsessive or traumatic intrusions. For example, in a recent study, Petrie, 
Booth, and Pennebaker (1998) compared the effects of expressive writing and thought suppression. These authors assigned the participants in their study to either of four conditions. More specifically, one group of subjects was invited to write for 15 minutes about a personal and emotional topic after which they were instructed to suppress thoughts about what they had written. A second group wrote about an emotional topic, but received no suppression instructions afterwards. In the third and fourth condition, subjects wrote about a nonpersonal and neutral topic, with and without subsequent suppression instructions, respectively. Immunological markers served as dependent measures (e.g., the number of lymphocytes found in the subjects' blood). Results indicated that there was only a marginal suppression effect ( $p=$ $.08)$, but a significant main effect for writing content $(p=.03)$, in that irrespective of suppression attempts, writing about self-relevant topics produced better health effects than writing about neutral topics. Thus, these results seem to indicate that expressive writing may overrule the detrimental effects of suppression. Likewise, in the Reynolds and Tarrier (1996) study, it was found that monitoring of traumatic intrusions had beneficial effects, even when it was accompanied by avoidant control strategies (e.g., thought suppression). The authors suggested that keeping a diary of intrusive recollections increases the amount of patients' perceived control over their thoughts. Perhaps, then, it is an increased sense of being in control rather than abstinence from thought suppression that constitutes the therapeutically active element in the studies referred to above. This may also explain why contrary to the predictions that flow from Wegner's work, some studies did find positive effects of thought stopping in the treatment of obsession (e.g., Kirk, 1983). However, in those studies, patients were first taught how to deliberately evoke obsessive thoughts. Only after they had mastered this, they were instructed to direct thought stopping techniques to any neutralizing attempts that might occur as a reaction to the obsessions. Again, the crucial element might be a sense of control over traumatic intrusions.

Secondly, while it has become common wisdom that confronting and expressing painful thoughts and emotions is therapeutically effective, there are several research findings that invite a more balanced view on this issue. For example, dysphoric individuals who are instructed to ruminate about themselves and their feelings have been found to be more pessimistic and impaired in their problem solving capabilities than are dysphoric individuals who distract their attention from their moods (see, for a review, Lyubomirsky, Caldwell, \& Nolen-Hoeksema, 1998). As another example, there are indications that unstructured exposure to trauma reminders might be harmful in the treatment of PTSD (e.g., Boudewyns \& Hyer, 1990; Johnson et al., 1996). On a related note, Solomon et al. (1992) found that treating PTSD veterans with prolonged exposure to military cues may result in exacerbation of PTSD symptoms. Commenting on these disappointing findings, Littrell (1998) concluded that confronting painful memories and thoughts will only yield benefit if the treatment also encourages cognitive restructuring of the traumatic experiences. It is worth citing the final remarks of Littrell's (1998) thoughtful review:

Revisiting painful emotion has the potential to improve health and psychological functioning. However, success is not explained by a purging/discharge mechanism or because the opposite of attending to emotion, viz., inhibition is precluded. Mere attention to feelings of distress can enhance distress. In order to preclude increasing distress as a consequence of revisiting trauma, some new response to the negative-emotion-eliciting stimulus (. .) must be found. (p. 96) 


\section{CONCLUDING REMARKS}

The pioneering work of Wegner and colleagues (1987) on the paradoxical effects of thought suppression has stimulated a vast amount of research (see, for a review, Clark \& Purdon, 1993). To date, more than 30 studies have documented immediate enhancement and/or rebound effects of thought suppression. Thus, it is safe to conclude that the paradoxical consequences of thought suppression represent robust phenomena. In contrast, the memory-out-of-order effect that is also ascribed to thought suppression (Wegner et al., 1996), is less well established. That is, a recent attempt to replicate this phenomenon with emotional target material yielded disappointing results (Rassin et al., 1997). Thus, parametric studies are needed to establish the boundary conditions of the memory-out-of-order effect of thought suppression (see below).

In literature, speculations about the involvement of thought suppression in psychopathology abound. These speculations often boil down to the idea that thought suppression contributes to the etiology or maintenance of obsessions, anxiety symptoms, depressive moods, or addictions. This idea possesses face validity given the robustness of the paradoxical effects of thought suppression in the laboratory. It is worth citing again Wegner et al.'s (1987) words: "The observed processes, though fairly tame in the laboratory, might conceivably create powerful mental preoccupations in natural settings" (p. 12). However, thought suppression studies that have been carried out in clinical samples do not support such a line of reasoning. Over the past few years, other theories about the origins of obsessions (e.g., Rachman, 1998) and worrying (Dugas et al., 1998) have been formulated and tested with favorable results. In these well-articulated accounts, thought suppression plays a relatively marginal role. Likewise, in the case of phobias and traumatic intrusions it is not at all clear whether thought suppression represents more than a symptomatic epiphenomenon. This is not to say that thought suppression maneuvers in these disorders should be ignored, but rather that their causal significance might have been overstated.

The links between thought suppression, cognitive intrusions, and psychopathology warrant further study. For example, few studies have examined Rachman's (1981) proposal that depressive mood impairs the controllability of intrusive cognitions, while anxiety enhances the threatening nature of such cognitions. Meanwhile, further progress in this area will critically depend on two issues that both have to do with the taxonomy of the basic phenomena involved. First, previous studies on thought suppression have generally adopted a broad definition of intrusive thinking. Worries, intrusive traumatic memories, anxious thoughts, and intrusive thoughts all have been treated as similar phenomena that may or may not become targets of thought suppression. While these manifestations of intrusive cognition share a number of features (e.g., Tallis \& De Silva, 1992), they also differ in important respects. Germane to this issue is the work of Clark (1992; Clark \& Claybourn, 1997) who found that one can distinguish between obsessive intrusions and negative automatic thoughts, with the former being more ego-dystonic and unacceptable than the latter. Likewise, worries and obsessive intrusions differ in that worries have a more verbal character, are more oriented towards future threats, and are less involuntary (e.g., Wells \& Morrison, 1994; Clark \& Claybourn, 1997). Additionally, recent work of Brewin and colleagues (Brewin, Christodoulides, \& Hutchinson, 1996; Reynolds \& Brewin, 1998) shows that there are important differences between intrusive thoughts and intrusive memories, with the former occurring more often in PTSD patients, depressive patients, and even 
normal subjects. Also, intrusive thought often contains elements such as reinterpretation or catastrophic elaboration. What is urgently needed, then, is a more accurate taxonomy of cognitive intrusions and the dimensions on which they vary. Such a taxonomy would enable researchers and clinicians to formulate more sophisticated hypotheses about the dynamics behind cognitive intrusions and the role played by thought suppression in these dynamics.

Secondly, it has become customary to think of thought suppression as a unitary phenomenon (Freeston, Ladouceur, Thibodeau, \& Gagnon, 1991). At the same time, there is a large, but scattered literature on the various avoidance and escape oriented strategies that people may resort to when they are confronted with intrusive cognitions. These strategies have been labeled blunting (Miller, 1992), cognitive avoidance (Foa \& Kozak, 1986), distraction (Baum, 1987), and retrieval inhibition (Bjork, 1989), to name but a few examples. To a certain extent, these concepts overlap with thought suppression, due to the fact they all assume the existence of inhibitory mechanisms that deactivate mental representations. Note, however, that there are also marked differences between these concepts in whether or not a maladaptive (i.e., counterproductive) quality is ascribed to them. For example, Miller (1992) concluded that in medical contexts, people who typically avoid threat-relevant information ("blunters") are often less distressed in response to health threats than are individuals who monitor threat-relevant cues ("monitors"). There are even indications that during anticipation of a medical visit, monitors display a higher frequency of intrusive thoughts than do blunters. However, whether blunting is an adaptive strategy depends on an array of conditions (e.g., nature and type of medical intervention, short versus long-term consequences of blunting). Findings such as these demonstrate that this research domain would also profit from a refined taxonomy of avoidant strategies. One promising starting point for such an endeavor is the Thought Control Questionnaire (TCQ) developed by Wells and Davies (1994). The TCQ consists of 30 items that were derived from a pool of avoidant strategies reported by anxiety disordered patients. More specifically, it covers 5 distinct maneuvers, namely distraction (e.g., "I keep myself busy"), social coping (e.g., "I talk to a friend about the thought"), worrying (e.g., "I worry about more minor things instead"), self-punishment (e.g., "I shout at myself for having the thought"), and reappraisal (e.g., "I try a different way of thinking about it"). It is highly unlikely that all these maneuvers have counterproductive effects that contribute to the persistence of psychopathology (e.g., Warda \& Bryant, 1998).

With these preliminary remarks in mind, we see several promising research avenues for future studies concerned with the links between thought suppression strategies and psychopathology. To begin with, it would be interesting to evaluate in a systematic fashion metacognitions about thought suppression strategies. Do people who engage in such strategies believe that the mere act of suppression proves that a certain target intrusion is less acceptable (e.g., Freeston et al., 1991)? Do they believe that certain thought suppression strategies are useful in helping to find solutions and preventing negative outcomes, as seems to be the case in pathological worrying (Dugas et al., 1998)? How do these metacognition beliefs about thought suppression relate to its counterproductive effects both within and outside the laboratory?

A second issue that warrants further study has to do with the complex interactions between mood, cognitive intrusions, cognitive coping strategies, and types of psychopathology. For example, some authors have found evidence to suggest that dysphoria reduces the acceptability of certain intrusions (e.g., Reynolds \& Salkovskis, 1992). In this way, mood states may trigger thought suppression of the sort described by Weg- 
ner (i.e., active resistance) and this may give rise to obsessive ruminations (Freeston et al., 1991; Rachman, 1978). Alternatively, the intrusions could elicit morbid preoccupation (i.e., attentive thinking) of the type found in worriers (Rachman, 1978). Obviously, these complex interactions deserve further study.

A third issue pertains to the effects of thought suppression strategies on memory. As things stand, it is unlikely that thought suppression strategies may account for dissociative amnesia (cf. supra). However, it is perfectly possible that thought suppression strategies have an impact on the formal characteristics of autobiographical memories. Germane to this issue are studies concerned with the phenomenon of overgeneralized memories which refers to the difficulty that some patients have in retrieving specific autobiographical memories (Williams, 1992, 1996). Overgeneralized memories have been documented in patients with depression (e.g., Williams, 1992), patients with PTSD (e.g., McNally, Lasko, Macklin, \& Pitman, 1995), and patients with OCD (e.g., Wilhelm, McNally, Baer, \& Florin, 1997), but are not found in normal subjects scoring high on neuroticism or depression (Merckelbach, Muris, \& Horselenberg, 1996). A recurring theme in studies exploring the origins of overgeneral memories is that these memories are tied to cognitive intrusions that occur against a background of depressive mood (e.g., Wilhelm et al., 1997; Kuyken \& Brewin, 1995). Avoidance strategies directed at these intrusions could promote a general retrieval inhibition (Kuyken \& Brewin, 1995) and/or could consume excessive cognitive capacity (Wilhelm et al., 1997). In either case, the result would be a relative inability to retrieve specific autobiographical memories. Perhaps, then, overgeneralized memories may become so extensive and profound that they are experienced as dissociative amnesia. So far, no study has looked specifically at the associations between intentional efforts to avoid distressing memories, overgeneralized memories, and dissociative amnesia. However, there is some indirect evidence suggesting that at least some persons who report periods of amnesia for traumatic events, in fact, refer to intentional avoidance of traumatic memories (Melchert \& Parker, 1997). Germane to this issue is also a study by Davis and Schwartz (1987) who found that repressors recall fewer negative autobiographical memories than do controls (see, for a more detailed analysis, Mendolia, Moore, \& Tesser, 1996). While such findings await replication, the co-occurrence of cognitive intrusions, depressive mood, avoidance strategies, and overgeneral memories seems to be well established and so, it provides a good starting point for further studies on the memory effects of thought suppression.

In sum, then, previous claims about the causal role of thought suppression in certain disorders have received little empirical support. Meanwhile, research on the pathogenic potential of thought suppression strategies has been hindered by a lack of detailed taxonomies of intrusive phenomena and avoidant strategies. To the extent that such taxonomies become available, more sophisticated hypotheses about the links between thought suppression strategies and psychopathology can be evaluated.

\section{REFERENCES}

American Psychiatric Association (APA). (1994). Diagnostic and statistical manual for mental disorders, fourth edition (DSM IV). Washington, DC: Author.

Amir, M., Kaplan, Z., Efroni, R., Levine, Y., Benjamin, J., \& Kotler, M. (1997). Coping styles in post-traumatic stress disorder (PTSD) patients. Personality and Individual Differences, 23, 399-405.

Baum, M. (1987). Distraction during flooding (exposure): Concordance between results in animals and man. Behaviour Research and Therapy, 25, 227-228. 
Becker, E. S., Rinck, M., Roth, W. T., \& Margraf, J. (1998). Don't worry and beware of white bears. Thought suppression in anxiety patients. Journal of Anxiety Disorders, 12, 39-55.

Bjork, R. A. (1989). Retrieval inhibition as an adaptive mechanism in human memory. In H. I. Roediger III \& F. I. M. Craik (Eds.), Varieties of memory and consciousness: Essays in honour of Endel Tulving (pp. 309-330). Hillsdale, NJ: Lawrence Erlbaum Associates.

Borkovec, M. J., \& Inz, J. (1990). The nature of worry in generalized anxiety disorder: A predominance of thought activity. Behaviour Research and Therapy, 28, 153-158.

Boudewyns, P. A., \& Hyer, L. (1990). Physiological response to combat memories and preliminary outcome in Vietnam veteran PTSD patients treated with direct therapeutic exposure. Behavior Therapy, 21, 63-87.

Bowers, K. S., \& Woody, E. Z. (1996). Hypnotic amnesia and the paradox of intentional forgetting. Journal of Abnormal Psychology, 105, 381-390.

Brett, E. A., \& Ostroff, R. (1985). Imagery and Post Traumatic Stress Disorder: An overview. American Journal of Psychiatry, 142, 417-424.

Brewin, C. R., Christodoulides, J., \& Hutchinson, G. (1996). Intrusive thoughts and intrusive memories in a nonclinical sample. Cognition and Emotion, 10, 107-112.

Brown, G. M. (1990). Knowledge retrieval and frequency maps. Ph.D. Thesis, University of Manchester, UK.

Bryant, R. A., \& Harvey, A. G. (1995). Avoidant coping style and post-traumatic stress following motor vehicle accidents. Behaviour Research and Therapy, 33, 631-635.

Cella, D. F., Perry, S. W., Kulchycky, S., \& Goodwin, C. (1988). Stress and coping in relatives of burn patients: A longitudinal study. Hospital and Community Psychiatry, 39, 159-166.

Cioffi, D., \& Holloway, J. (1993). Delayed costs of suppressed pain. Journal of Personality and Social Psychology, 64, 274-282.

Clark, D. A. (1992). Depressive, anxious, and intrusive thoughts in psychiatric inpatients and outpatients. Behaviour Research and Therapy, 30, 93-102.

Clark, D. M., Ball, S., \& Pape, D. (1991). An experimental investigation of thought suppression. Behaviour Research and Therapy, 29, 253-257.

Clark, D. A., \& Claybourn, M. (1997). Process characteristics of worry and obsessive intrusive thoughts. Behaviour Research and Therapy, 35, 1139-1141.

Clark, D. A., \& Purdon, C. (1993). New perspectives for a cognitive theory of obsessions. Australian Psychologist, 28, 161-167.

Clark, D. M., Winton, E., \& Thynn, L. (1993). A further experimental investigation of thought suppression. Behaviour Research and Therapy, 31, 207-210.

Cloitre, M., Cancienne, J., Brodsky, B., Dulit, R., \& Perry, S. W. (1996). Memory performance among women with parental abuse histories: Enhanced directed forgetting or directed remembering? Journal of Abnormal Psychology, 105, 204-211.

Conway, M., Howell, A., \& Giannopoulos, C. (1991). Dysphoria and thought suppression. Cognitive Therapy and Research, 15, 153-166.

Creamer, M., Burgess, P., \& Pattison, P. (1992). Reaction to trauma: A cognitive processing model. Journal of Abnormal Psychology, 101, 452-459.

Davis, P. J., \& Schwartz, G. E. (1987). Repression and the inaccessibility of affective memories. Journal of Personality and Social Psychology, 52, 155-162.

Dugas, M. J., Gagnon, F., Ladouceur, R., \& Freeston, M. H. (1998). Generalized anxiety disorder: A preliminary test of a conceptual model. Behaviour Research and Therapy, 36, 215-226.

Erdelyi, M. H. (1993). Repression: The mechanism and the defense. In D. M. Wegner \& J. W. Pennebaker (Eds.), Handbook of mental control (pp. 126-148). Englewood Cliffs, NJ: Prentice Hall.

Esterling, B. A., L’Abate, L., Murray, E. J., \& Pennebaker, J. W. (1999). Empirical foundations for writing in prevention and psychotherapy: Mental and physical health outcomes. Clinical Psychology Review, 19, 79-96.

Eysenck, H. J. (1985). Decline and fall of the Freudian empire. Harmondsworth, UK: Middlesex.

Foa, E. B., \& Kozak, M. J. (1986). Emotional processing of fear: Exposure to corrective information. Psychological Bulletin, 99, 20-35.

Foa, E. B., Riggs, D. S., \& Gershuny, B. S. (1995). Arousal, numbing, and intrusion: Symptom structure of PTSD following assault. American Journal of Psychiatry, 152, 116-120.

Frankel, F. H. (1990). Hypnotizability and dissociation. American Journal of Psychiatry, 147, 823-829.

Freeston, M. H., Ladouceur, R., Thibodeau, N., \& Gagnon, F. (1991). Cognitive intrusions in a non-clinical population.1. Response style, subjective experience, and appraisal. Behaviour Research and Therapy, 29, 585-597.

Freud, A. (1946). The ego and the mechanisms of defense. (C. Baines, Trans.). New York: International Universities Press. (Original work published in 1936) 
Freud, S. (1955). Notes upon a case of obsessional neurosis. (A. Strachey \& J. Strachey, Trans.). In J. Strachey (Ed.), The standard edition of the complete psychological works of Sigmund Freud, vol. 10. London: Hogarth. (Original work published in 1909)

Haaga, D. A. F., \& Allison, M. L. (1994). Thought suppression and smoking relapse: A secondary analysis of Haaga (1989). British Journal of Clinical Psychology, 33, 327-331.

Harvey, A. G., \& Bryant, R.A. (1998a). The role of valence in attempted thought suppression. Behaviour Research and Therapy, 36, 757-763.

Harvey, A. G., \& Bryant, R. A. (1998b). The effect of attempted thought suppression in acute stress disorder. Behaviour Research and Therapy, 36, 583-590.

Holmes, D. S. (1990). The evidence for repression: An examination of sixty years of research. In J. L. Singer (Ed.), Repression and dissociation: Implications for personality theory, psychopathology, and health (pp. 85-102). Chicago: The University of Chicago Press.

James, W. (1890). Principles of psychology. New York: Holt.

Johnson, H. M. (1994). Processes of successful intentional forgetting. Psychological Bulletin, 116, $274-292$.

Johnson, D. R., Rosenheck, R., Fontana, A., Lubin, H., Charney, D., \& Southwick, S. (1996). Outcome of intensive inpatient treatment of combat-related posttraumatic stress disorder. American Journal of Psychiatry, 153, 771-777.

Kelly, A. E., \& Kahn, J. H. (1994). Effects of suppression of personal intrusive thoughts. Journal of Personality and Social Psychology, 66, 998-1006.

Kirk, J. (1983). Behavioural treatment of obsessional-compulsive patients in routine clinical practice. Behaviour Research and Therapy, 21, 57-62.

Koss, M. P., Figueredo, A. J., Bell, I., Tharan, M., \& Tromp, S. (1996). Traumatic memory characteristics: A cross-validated mediational model of response to rape among employed women. Journal of Abnormal Psychology, 105, 421-432.

Kuyken, W., \& Brewin, C. R. (1994). Intrusive memories of childhood abuse during depressive episodes. Behaviour Research and Therapy, 32, 525-528.

Kuyken, W., \& Brewin, C. R. (1995). Autobiographical memory functioning in depression and reports of early abuse. Journal of Abnormal Psychology, 104, 585-591.

Lawrence, J. W., Fauerbach, J., \& Munster, A. (1996). Early avoidance of traumatic stimuli predicts chronicity of intrusive thoughts following burn injury. Behaviour Research and Therapy, 34, 643-646.

Lavy, E. H., \& Van den Hout, M. (1990). Thought suppression induces intrusions. Behavioural Psychotherapy, $18,251-258$.

Lilienfeld, S. O., \& Loftus, E. F. (1998). Repressed memories and World War II: Some cautionary notes. Professional Psychology: Research and Practice, 29, 471-475.

Littrell, J. (1998). Is the reexperience of painful emotion therapeutic? Clinical Psychology Review, 18, 71-102.

Lyubomirsky S., Caldwell, N. D., \& Nolen-Hoeksema, S. (1998). Effects of ruminative and distracting responses to depressed mood on retrieval of autobiographical memories. Journal of Personality and Social Psychology, 75, 166-177.

Macrae, C. N., Bodenhausen, G. V., Milne, A. B., \& Jetten, J. (1994). Out of mind but back in sight: Stereotypes on the rebound. Journal of Personality and Social Psychology, 67, 808-817.

Marks, I. M. (1987). Fears, phobias, and rituals: Panic, anxiety, and their disorders. New York: Oxford University Press.

McFarlane, A. C. (1988). The longitudinal course of posttraumatic morbidity: The range of outcomes and their predictors. The Journal of Nervous and Mental Disease, 176, 30-40.

McNally, R. J., Lasko, N.B., Macklin, M. Z., \& Pitman, R. L. (1995). Autobiographical memory disturbance in combat-related posttraumatic stress disorder. Behaviour Research and Therapy, 33, 619-630.

McNally, R. A., Metzger, L. J., Lasko, N. B., Clancy, S. A., \& Pitman, R. A. (1998). Directed forgetting of trauma cues in adult survivors of childhood sexual abuse with and without posttraumatic stress disorder. Journal of Abnormal Psychology, 107, 596-601.

Melchert, T. P., \& Parker, R. L. (1997). Different forms of childhood abuse and memory. Child Abuse E Neglect, 21, 125-135.

Mendolia, M., Moore, J., \& Tesser, A. (1996). Dispositional and situational determinants of repression. Journal of Personality and Social Psychology, 70, 856-867.

Merckelbach, H., Muris, P., \& Horselenberg, R. (1996). Correlates of overgeneral memories in normal subjects. Behavioural and Cognitive Psychotherapy, 24, 109-115.

Merckelbach, H., Muris, P., Van den Hout, M., \& De Jong, P. (1991). Rebound effects of thought suppression: Instruction dependent? Behavioural Psychotherapy, 19, 225-238.

Miller, S. M. (1992). Monitoring and blunting in the face of threat: Implications for adaptation and health. 
In L. Montada, S. H. Filipp, \& M. J. Lerner (Eds.), Life crises and experiences of loss in adulthood (pp. 255273). Englewood Cliffs, NJ: Erlbaum.

Muris, P., De Jongh, A., Merckelbach, H., Postema, S., \& Vet, M. (1998). Thought suppression in phobic and non-phobic dental patients. Anxiety, Stress, and Coping, 11, 275-287.

Muris, P., \& Merckelbach, H. (1991). Het effect van gedachte-onderdrukking: Een quasi-experiment (The effect of thought suppression: A quasi-experiment). Directieve Therapie, 11, 119-126.

Muris, P., \& Merckelbach, H. (1997). Suppression and dissociation. Personality and Individual Differences, 23, 523-525.

Muris, P., Merckelbach, H., \& De Jong, P. (1993). Verbalization and environmental cueing in thought suppression. Behaviour Research and Therapy, 31, 609-612.

Muris, P., Merckelbach, H., \& Clavan, M. (1997). Abnormal and normal compulsions. Behaviour Research and Therapy, 35, 249-252.

Muris, P., Merckelbach, H., \& Horselenberg, R. (1996). Individual differences in thought suppression. The white bear suppression inventory: Factor structure, reliability, validity and correlates. Behaviour Research and Therapy, 34, 501-513.

Muris, P. Merckelbach, H., Horselenberg, R., Sijsenaar, M., \& Leeuw, I. (1997). Thought suppression in spider phobia. Behaviour Research and Therapy, 35, 769-774.

Muris, P., Merckelbach, H., Van den Hout, M., \& De Jong, P. (1992). Suppression of emotional and neutral material. Behaviour Research and Therapy, 30, 639-642.

Myers, L. B., Brewin, C. R., \& Power, M. J. (1998). Repressive coping and the directed forgetting of emotional material. Journal of Abnormal Psychology, 107, 141-148.

Palfai, T. P., Monti, P. M., Colby, S. M., \& Rohsenow, D. J. (1997). Effects of suppressing the urge to drink on the accessibility of alcohol outcome expectancies. Behaviour Research and Therapy, 35, 59-65.

Pennebaker, J. W. (1993). Putting stress into words: Health, linguistic and therapeutic implications. Behaviour Research and Therapy, 31, 539-548.

Petrie, K. J., Booth, R. J., \& Pennebaker, J. W. (1998). The immunological effects of thought suppression. Journal of Personality and Social Psychology, 75, 1264-1272.

Pope, H. G., Hudson, J. I., Bodkin, J. A., \& Oliva, P. (1998). Questionable validity of 'dissociative amnesia' in trauma victims. British Journal of Psychiatry, 172, 210-215.

Rachman, S. J. (1978). An anatomy of obsessions. Behavior Analysis and Modification, 2, 255-278.

Rachman, S. J. (1981). Unwanted intrusive cognitions. Advances in Behaviour Research and Therapy, 3, 89-99.

Rachman, S. (1993). Obsessions, responsibility and guilt. Behaviour Research and Therapy, 31, 149-154.

Rachman, S. (1997). A cognitive theory of obsessions. Behaviour Research and Therapy, 35, 793-802.

Rachman, S. (1998). A cognitive theory of obsessions: Elaborations. Behaviour Research and Therapy, 36, 385401.

Rachman, S., \& De Silva, P. (1978). Abnormal and normal obsessions. Behaviour Research and Therapy, 16, 233-248.

Rassin, E., Muris, P., Schmidt, H., \& Merckelbach, H. (in press). Thought-action fusion, thought suppression, and obsessive-compulsive symptoms: A structural equation modeling approach. Behaviour Research and Therapy.

Rassin, E., Merckelbach, H., \& Muris, P. (1997). Effects of thought suppression on episodic memory. Behav iour Research and Therapy, 35, 1035-1038.

Rassin, E., Merckelbach, H., Muris, P., \& Spaan, V. (1999). Thought-action fusion as a causal factor in the development of intrusions. Behaviour Research and Therapy, 37, 231-237.

Rassin, E., Merckelbach, H., Muris, P., \& Stapert, S. (1999). Suppression and ritualistic behaviour in normal participants. British Journal of Clinical Psychology, 38, 195-201.

Reynolds, M., \& Brewin, C. R. (1998). Intrusive cognitions, coping strategies and emotional responses in depression, post-traumatic stress disorder and a non-clinical population. Behaviour Research and Therapy, 36, 135-147.

Reynolds, M., \& Salkovskis, P. M. (1992). Comparison of positive and negative intrusive thoughts and experimental investigation of the differential effects of mood. Behaviour Research and Therapy, 30, 273-281.

Reynolds, M., \& Tarrier, N. (1996). Monitoring of intrusions in post-traumatic stress disorder: A report of single case studies. British Journal of Medical Psychology, 69, 371-379.

Roemer, E., \& Borkovec, T. D. (1994). Effects of suppressing thoughts about emotional material. Journal of Abnormal Psychology, 103, 467-474.

Rutledge, P.C., Hollenberg, D., \& Hancock, R. A. (1993). Individual differences in the Wegner rebound effect: Evidence for a moderator variable in thought rebound following thought suppression. Psychological Reports, 72, 867-880.

Salkovskis, P. M., \& Harrison, J. (1984). Abnormal and normal obsessions: A replication. Behaviour Research and Therapy, 22, 549-552. 
Salkovskis, P. M., \& Reynolds, M. (1994). Thought suppression and smoking cessation. Behaviour Research and Therapy, 32, 193-201.

Salkovskis, P. M., \& Westbrook, D. (1989). Behaviour therapy and obsessional ruminations: Can failure be turned into success? Behaviour Research and Therapy, 27, 149-160.

Shafran, R., Thordarson, D. S., \& Rachman, S. (1996). Thought-action fusion in Obsessive Compulsive Disorder. Journal of Anxiety Disorders, 10, 379-391.

Shipherd, J. C., \& Beck, J. G. (1999). The effects of suppressing trauma-related thoughts on women with rape-related posttraumatic stress disorder. Behaviour Research and Therapy, 37, 99-112.

Smári, J., Birgisdóttir, A. B., \& Brynjólfsdóttir, B. (1995). Obsessive-compulsive symptoms and suppression of personally relevant unwanted thoughts. Personality and Individual Differences, 18, 621-625.

Smári, J., Sigurjónsdóttir, H., \& Sæmundsdóttir, I. (1994). Thought suppression and obsession-compulsion. Psychological Reports, 75, 227-235.

Solomon, Z., Shalev, A., Spiro, S., Dolev, A., Bleich, A., Waysman, M., \& Cooper, S. (1992). Negative psychometric outcomes: Self-report measures and a follow-up telephone survey. Journal of Traumatic Stress, 5, 225-246.

Tallis, F., \& De Silva, P. (1992). Worry and obsessional symptoms: A correlational analysis. Behaviour Research and Therapy, 30, 103-105.

Terr, L. C. (1991). Childhood traumas: An outline and overview. American Journal of Psychiatry, 148, 10-19.

Terr, L. (1993). Unchained memories: True stories of traumatic memories lost and found. New York: Basic books.

Trinder, H., \& Salkovskis, P. M. (1994). Personally relevant intrusions outside the laboratory: Long-term suppression increases intrusion. Behaviour Research and Therapy, 32, 833-842.

Van den Hout, M., Merckelbach, H., \& Pool, K. (1996). Dissociation, reality monitoring, trauma and thought suppression. Behavioural and Cognitive Psychotherapy, 24, 97-108.

Vaughan, K., \& Tarrier, N. (1992). The use of image habituation training with post-traumatic stress disorder. British Journal of Psychiatry, 161, 658-664.

Warda, G., \& Bryant, R. A. (1998). Thought control strategies in acute stress disorder. Behaviour Research and Therapy, 36, 1171-1175.

Wegner, D. M. (1989). White bears and other unwanted thoughts: Suppression, obsession, and the psychology of mental control. London: The Guilford Press.

Wegner, D. M. (1994). Ironic processes of mental control. Psychological Review, 101, 34-52.

Wegner, D. M., \& Erber, R. (1992). The hyperaccessibility of suppressed thoughts. Journal of Personality and Social Psychology, 63, 903-912.

Wegner, D. M., Quillian, F., \& Houston, C. (1996). Memories out of order: Thought suppression and the disassembly of remembered experience. Journal of Personality and Social Psychology, 71, 680-691.

Wegner, D. M., Schneider, D. J., Carter, S. R., \& White, T. L. (1987). Paradoxical effects of thoughts suppression. Journal of Personality and Social Psychology, 53, 5-13.

Wegner, D. M., Schneider, D. J., Knutson, B., \& McMahon, S. R. (1991). Polluting the stream of consciousness: The effect of thought suppression on the mind's environment. Cognitive Therapy and Research, 15, $141-152$.

Wegner, D. M., Shortt, J. W., Blake, A. W., \& Page, M. S. (1990). The suppression of exciting thoughts. Journal of Personality and Social Psychology, 58, 409-418.

Wegner, D. M., \& Zanakos, S. (1994). Chronic thought suppression. Journal of Personality, 62, 615-640.

Wells, A., \& Davies, M. I. (1994). The thought control questionnaire: A measure of individual differences in the control of unwanted thoughts. Behaviour Research and Therapy, 32, 871-878.

Wells, A., \& Morrison, A. P. (1994). Qualitative dimensions of normal worry and normal obsessions: A comparative study. Behaviour Research and Therapy, 32, 867-870.

Wenzlaff, R. M., Wegner, D. M., \& Roper, D. (1988). Depression and mental control: The resurgence of unwanted negative thoughts. Journal of Personality and Social Psychology, 55, 882-892.

Wessel, I. (1997). Attentional narrowing as a model for partial amnesia. Maastricht, The Netherlands: Datawyse.

Wilhelm, S., McNally, R. J., Baer, L., \& Florin, I. (1997). Autobiographical memory in obsessive-compulsive disorder. British Journal of Clinical Psychology, 36, 21-31.

Williams, J. M. G. (1992). Autobiographical memory and emotional disorders. In S. Christianson (Ed.), The handbook of emotion and memory: Research and theory (pp. 451-477). London: Lawrence Erlbaum Associates, Publishers.

Williams, J. M. G. (1996). Depression and the specificity of autobiographical memory. In D. Rubin. (Ed.), Remembering our past: Studies in autobiographical memory (pp. 244-267). Cambridge, UK: Cambridge University Press. 